\section{(K)ein Notfall}

- An einem Sonntagvormittag rief eine mir gut bekannte Frau aus der Nachbarschaft an: Ihre Tochter fühle sich nicht wohl, klage über Halsschmerzen - und am übernächsten Tag stünde zu allem Überfluss noch eine schriftliche Abiturprüfung an. Um die gestressten Damen möglichst zu schonen, verwies ich sie nicht an den ärztlichen Bereitschaftsdienst, sondern versprach vorbeizukommen.

Angesichts der sehr vitalen jungen Dame, die mich erwartete, war ich erleichtert - einerseits, weil kein behandlungsbedürftiger medizinischer Notfall vorlag, andererseits, weil die Teilnahme an der bevorstehenden Prüfung somit auch nicht gefährdet schien. Ich beruhigte Mutter und Tochter, erklärte, der leicht gerötete Rachenring wiese auf einen Virusinfekt hin, den man nicht gezielt behandeln, wohl aber beeinflussen könne. Ich empfahl, den Tag in Ruhe zu Hause zu verbringen, heißen Tee mit Honig zu trinken, das bewährteste homöopathische Mittel aus der gut bestückten Hausapotheke einzunehmen und bei weiter bestehendem Krankheitsgefühl am Montag den Hausarzt aufzusuchen.

Ich staunte nicht schlecht, als die Mutter mir am Montagabend vorwurfsvoll mit- teilte, man habe den ganzen Vormittag mit der Suche nach Ersatz für den abwesenden Hausarzt verbringen müssen. Auch habe die Tochter ein Antibiotikum verschrieben bekommen, was ich ja für unnötig gehalten hätte. Mit gelindem Ärger und dem Vorsatz, mich künftig derartiger Nachbarschaftshilfe zu enthalten, war der Vorfall für mich erledigt.

Einige Wochen später - nach bestandenem Abitur - gestand mir die Mutter, ihre Tochter hätte als "naturwissenschaftlich gebildet" meine Hausmittel von vornherein als unprofessionell abgelehnt. Auch habe man mehrere Niedergelassene aufsuchen müssen, bis endlich einer die Halsschmerzen widerwillig antibiotisch abdecken wollte. Die Tochter habe auch sehr rasch mögliche Nebenwirkungen vom Beipackzettel an sich entdeckt und die Medikation nach wenigen Tabletten abgebrochen - folgenlos, denn nach der Prüfung ging es ihr überraschenderweise sowieso wieder gut.

Da dämmerte mir, dass meine Sorgen um eine "gute" Medizin vielleicht der geringste Teil des Problems sein könnten!

Dr. Antonie Demling =

\section{Gemütsruhe}

— In meiner Praxis in einem abgelegenen Tal in Südtirol kommt es immer wieder zu Ereignissen, die im Nachhinein so unwirklich erscheinen, dass ich sie selber kaum zu glauben vermag. Die Leute in diesem Tal sind von ausgesuchter Herzlichkeit, aber auch Härte zu sich selber, so nach dem Motto "man muss den Schmerz aushalten".

So auch kürzlich: Ein Patient wartete eine halbe Stunde in aller Gemütsruhe, bis er an die Reihe kam. Er war etwas im Windschatten unseres Sekretariates gesessen und so hatten ihn auch die anderen Kollegen wohl nicht gesehen. Der Mann, ca. 45
Jahre alt, hatte eine ca. $5 \mathrm{~cm}$ große, unterhalbe des Kinnes klaffende Wunde, aus der es ordentlich auf sein Leibchen heruntertropfte, trotz Sacktuch, dass er sich draufhielt. Eine kleine Blutlache hätte sich wohl bald gebildet, wenn wir ihn nicht aufgerufen hätten.

Er meinte dazu nur, "Ich kann ja warten, so schlimm ist das ja alles gar nicht." Ein Teil der Melkmaschine habe ihn erwischt.

Die Wundversorgung ist Gott sei Dank ohne große Probleme und zügig verlaufen und die Wunde schön verheilt.

Dr. Claudia Petroni, Sarntal, Südtirol . 